is to be controlled in this high risk population.

I SIMMS

M A CATCHPOLE

PHLS Communicable Disease Surveillance Centre,

61 Colindale Avenue, London SW9 5DF, UK A J ROBINSON

C LAAS

Department of Genitourinary Medicine, The Mortimer Market Centre,

London, UK

Correspondence to: $\mathrm{Mr}$ I Simms.

1 Hay PE, Thomas BJ, Horner PJ, MacLeod E, Renton AM, Taylor-Robinson D. Chlamydia trachomatis in women: the more you look, the more you find. Genitourin Med 1994;70 97-100.

2 Paul ID, Crowley T, Milne JD, Caul EO. A comparison of urine and urethral swabbing for the diagnosis of $C$ trachomatis infection in males. Serodiagn Immunother Infect Dis 1995; males. Serodi 80 .

3 Sexually transmitted diseases quarterly report: genital infection with Chlamydia trachomatis in England and Wales. Communicable Disease Report Weekly 1996;6:190-1.

4 British Co-operative Clinical Group. Survey of diagnostic facilities for Chlamydia trachomatis and herpes simplex virus, 1984. Genitourin Med 1987;61:26-7.

5 Royal College of Physicians Committee on Genitourinary Medicine. Chlamydial diagnostic services in the UK and Eire: current nostic services in the UK and Eire: current
facilities and perceived needs. Genitourin Med 1987;63:371-4.

6 Radcliffe KW, Rowen D, Mercey DE, Bingham JS. Survey of the management of Chlamydia trachomatis infection of the cervix. Genitourin Med 1991;67:41-3.

Accepted for publication 4 December 1996

Same day testing for HIV: 1 year's experience in a district general hospital and at an alternative site

In the Department of Health's white paper, the Health of the Nation ${ }^{1}$ sexual health, including HIV and AIDS, is identified as one of the key areas of health targeting. Counselling and screening for HIV forms an important part of sexual health and this service should be widely available. Experience suggests, as stated in HIVIAIDS and Sexual Health, ${ }^{2}$ that where available many would prefer to attend a clinic separate from current services. In response to the executive letter from the Department of Health, ${ }^{3}$ a same day HIV counselling and testing service was developed at Bolton General Hospital, and at an alternative site in the town centre. We present the results of this service over a 12 month period.

In May 1994, a same day testing service was introduced in addition to the routine clinic testing, available 1 day a week by appointment only, both in the hospital department and also at an alternative (town centre) site. The same day service was advertised locally. All patients attending for HIV testing were given pre- and post-test counselling and sexual health advice at both sites.

Over the 12 month period, 218 patients made appointments for same day HIV antibody testing. The default rate for the same day testing service was $22 \cdot 5 \%(n=49)$. The same day hospital site had a higher attendance rate than the alternative site (table). There was one positive HIV antibody result in a homosexual man who was asymptomatic. Six patients requested testing because of a possible risk of HIV infection from overseas medical treatment. All of these opted to be tested at the clinic site, their choice perhaps reflecting concerns which they felt
Predominant risk factors and default rates for patients tested at the same day testing sites

\begin{tabular}{lll}
\hline & $\begin{array}{l}\text { Clinic site } \\
(n=94)\end{array}$ & $\begin{array}{l}\text { Alternative } \\
\text { site }(n=65)\end{array}$ \\
\hline Default rate & $22 \cdot 3 \%$ & $25 \cdot 3 \%$ \\
Male & $(\mathrm{n}=27)$ & $(\mathrm{n}=22)$ \\
Female & 60 & 39 \\
Homosexual & 34 & 26 \\
Heterosexual & 96 & 14 \\
Bisexual & 62 & 38 \\
Intravenous drugs & 9 & 1 \\
Overseas medical & 9 & 9 \\
treatment & 6 & 0 \\
Others, for example, & & 3 \\
$\quad$ occupational & 6 & 3 \\
\hline
\end{tabular}

might be better addressed in a hospital setting. Same day testing accounted for $41.8 \%$ of the total number of HIV tests within the department.

The current arrangement for HIV antibody testing in genitourinary medicine clinics within the hospital setting has the advantage that the service is widely available and testing is performed in an anonymous and confidential manner. This testing service may have its drawbacks for certain patients who find attending a genitourinary medicine clinic a daunting prospect, especially if the department is based inside a large hospital which is not readily accessible from the local town centre. Other authors have reported successful same day testing services within city centres ${ }^{4}$; however, this is the first paper to report results from a district general hospital setting together with the use of an alternative site. Our results show that a significant proportion of patients opted for the same day testing service and when given the choice of site, patients were more likely to attend the same day hospital service than the alternative site. Further work is required to ascertain reasons behind the high default rate of patients requesting same day HIV testing, as little is known about the sociodemographic details and risk factors among this group. Future evaluation should include qualitative feedback from patients on the issues surrounding testing to determine the optimal testing procedure and site.

DAVID NUNNS GUNDI KIEMLE

JACKIE ROGERS HELEN O'NEILI KATE HAWKESFORD ERIC CURIESS

Bolton Centre for Sexual Health Bolton General Hospital, Farnworth,

Bolton BL4 OFR

1 Secretary of State for Health. The health of the nation: a strategy for health in England. nation: a strategy for health in

2 HIVIAIDS and sexual health. London: Department of Health, 1992 (HSSH J1835)

3 Department of Health Guidance: additional testing site for HIV. London: Department of Health, 1992 (PLCMO (92)5, appendix 1).

4 Bor R. HIV seroprevalence in a London sameday testing clinic. AIDS 1994;8:697-700.

Accepted for publication 28 January 1997

\section{Survival and treatment of AIDS patients 1984-1993}

Hillman et al seem somewhat confused with their contribution to the debate regarding the place and value of HIV service provision and whether this should be through larger or smaller centres. ${ }^{1}$ Assessing survival from AIDS is not a measure of quality of service.
Indeed, survival from AIDS may decrease but quality of life and overall survival from HIV infection may be improved. ${ }^{2}$ We have shown previously in a study involving a large number of patients that survival from AIDS may be influenced by the time of presentation-that is, that survival may increase if the $ه$ AIDS defining illness occurs coincident with $\frac{\mathbb{D}}{2}$ the first positive HIV antibody test. ${ }^{3}$ This does not mean, as Hillman et al assert, that we are questioning the benefit of medical intervention-quite the reverse. We propose that the development of AIDS has been? delayed by medical intervention. Indeed, in their paper Hillman et al support the asser- $\stackrel{\vec{D}}{\vec{D}}$ tion that effective intervention may reduce? survival from AIDS; they saw a reduction in 흘 median survival over time in their patients.

Furthermore, the authors suggest that in our study we both failed to acknowledge improvements in survival made before the study period from St Mary's Hospital and $\vec{O}$ did not adjust for case $\mathrm{mix}$ in the two arms. ${ }^{3}$ In fact, earlier data were acknowledged and referenced and the case mix of the two arms was described in detail.

Hillman et al conclude in their paper that ${ }^{\omega}$ smaller units may allow a more informal and ${ }^{*}$ intimate setting for patients to be treated. $\vec{\infty}$ This, however, is not supported by their data and is, therefore, only an unsubstantiatedo opinion. Others, we are sure, would argue against it. Department of Genitourinary Medicine, St Mary's Hospital, $\overrightarrow{c o}$ London W2 $1 N Y$ ? MARK POZNANSKY

Division of Infectious Diseases Medicine, Harvard Medical School, Boston, MA 02115, USA

1 Hillman RJ, Beck EJ, Mandalia $S$, 응 Satterthwaite H, Rogers PA, Forster GE, et $\mathrm{\Phi}$ al. Survival and treatment of AIDS patients 1984-1993: experience of a smaller East London HIV centre. Gentiourin Med 1997;73:44-8.

2 Coker RJ, Poznansky MC. Physicians' experience and survival in patients with AIDS. $N$ Engl f Med 1996;335:349.

3 Poznansky $M$, Coker $R$, Skinner $C$, Hill $A$, Bailey S, Whitaker L, et al. HIV positive patients first presenting with an AIDS defining patients first presenting with an AIDS defining 1995;311:156-8.

Accepted for publication 21 February 1997

MATTERS ARISING

Who goes to sexually transmitted diseases clinics? Results from a national population survey (Genitourin Medo 1996;72:197-202)

We read with great interest Dr A M Johnson and colleagues' sexual behaviour survey of GUM clinic attenders, published in Genitourin Med. The findings of the study now make available good population based data on the characteristics of genitourinary? medicine clinic attenders, which will be applicable to many aspects of further research and service planning.

However, we wish to comment on one point made by the authors, in respect of data from GUM clinics being recorded on diagnostic cases rather than on individuals. It may not be widely known that, since April 